\title{
Knowledge and approaches of married men applying to a primary healthcare center in Istanbul about IUD: A qualitative study
}

\author{
(1) Muhammed Fatih Onsuz, ${ }^{1}$ (1) Seyhan Hidiroglu, ${ }^{2}$ (D) Melda Karavus ${ }^{2}$ \\ ${ }^{1}$ Department of Public Health, Osmangazi University Faculty of Medicine, Eskisehir, Turkey \\ ${ }^{2}$ Department of Public Health, Marmara University Faculty of Medicine, Istanbul, Turkey
}

\begin{abstract}
OBJECTIVE: This study aims to determine the knowledge and approach of men applying to a primary health care center about IUD by adopting qualitative research methods.

METHODS: This study was qualitative research realized using an in-depth interview method. The interview was carried with 15 married men in a primary health care center in Umraniye, using 15 semi-structured interview questions.

RESULTS: Knowledge of the men in this study about IUD and family planning was inadequate. Participants generally determined the advantages of IUD with its superiority over other methods. Adverse effects of IUD on women and men during intercourse were stated. Knowledge of men about IUD, its side effects and disadvantages were generally composed of misinformation and rumours about the subject.

CONCLUSION: Men do not have adequate information and knowledge on family planning and IUD. Training provided by the health personnel might have a considerable role in demolishing misinformation and rumors and may augment the level of knowledge about IUD.
\end{abstract}

Keywords: Attitudes; intrauterine device; knowledge; married man; qualitative study.

Cite this article as: Onsuz MF, Hidiroglu S, Karavus M. Knowledge and approaches of married men applying to a primary healthcare center in Istanbul about iud: A qualitative study. North Clin Istanb 2019;6(4):374-378.

E very year, 46 million unwanted pregnancies are eventuated with abortion [1]. In Turkey, about 2 million pregnancies occur, and 5,0\% percent of them end up with abortion, which brings about unfavourable effects on the health of families and individuals [2]. Every year, 187 million unwanted pregnancy, 60 million unplanned birth, and 105 million abortions are prevented by applying family planning methods [3]. Family planning methods are classified as modern and traditional methods. According to Turkish Population and Health Research (TNSA) data, $73.5 \%$ of married women in Turkey, do not prefer any contraceptive methods, and $47.4 \%$ of women using a contraceptive method prefer modern methods. The most favorable method within modern methods is IUD, with $16.8 \%$ [2]. IUD is a very effective (99\%), reversible, cheap and easy method to use. Moreover, IUD prevents pregnancy effectively five to ten years. Intense utilization of this method might decrease the number of unwanted pregnancy more effectively than other methods [4].

Although family planning is supposed to be a mutual responsibility of couples, largely, it is on women's responsibility [5]. Men have critical responsibilities on family planning and prevention of unwanted pregnancy, whereas the level of contribution of men in family plan-

Received: February 21, 2018 Accepted: December 06, 201X Online: July 02, 2019

Correspondence: Dr. Muhammed Fatih ONSUZ. Eskisehir Osmangazi Universitesi Tip Fakultesi, Halk Sagligi Anabilim Dali, Meselik Kampusu, 26480 Odunpazari, Eskisehir, Turkey.

Tel: +90222 2392979 - 4518 e-mail: fatihonsuz@yahoo.com

(c) Copyright 2019 by Istanbul Provincial Directorate of Health - Available online at www.northclinist.com 
ning is very low in developing countries and in Turkey [6, 7]. Particularly, the level of utilization of modern family planning techniques for men is observed to be very low. There is not enough information about the behaviours of men towards family planning. There are no clear answers to these questions. For example, what are the factors affecting behaviours and approaches of men towards family planning; or are they against to use contraceptive methods? Using qualitative research methods, this kind of questions can be answered because qualitative researches are influential for understanding and interpreting the humanitarian dimension of a subject. Especially, they provide meaningful data for perceiving thoughts, emotions, believes, behaviours and relationships about the subject [8]. There are limited and insufficient research and information about knowledge, approaches and thoughts of men about the IUD, which is one of the most common modern contraceptive methods. Under this information, it is recognized that there is a requirement for having qualitative research about approaches and knowledge of men about IUD.

Using a qualitative research method, the present research aims to determine the knowledge and approaches of married men applying to a primary healthcare center in Istanbul about IUD.

\section{MATERIALS AND METHODS}

This research was qualitative and carried out in Umraniye, a district of Istanbul, with married men. Umraniye allowing immigrants from other cities of Turkey, it is a district where more socio-economically disadvantageous people live. This research was conducted with 15 married men applying to a primary health care center in Umraniye and accepting to participate in this research. In-depth interview technique was adopted to collect data. Since this research was qualitative, the size of the sample was not measured and the men participating in the focus group were determined using accidental sampling, which is a haphazard sampling technique. In the application of this research, the principles of Helsinki Declaration were taken into consideration and necessary permissions were taken from the local managers for the research. In addition, permissions of participators were taken for their informed consents and sound recordings.

In the first phase, socio-demographic features of the participators were gathered by adopting face to face interview technique. In the second phase, interviews were executed with participators using an interview guide composed of 15 semi-structured questions. The interviews were suitable to the participators answering time, and when the participators started to repeat their views, the interviews were terminated. The interviews were processed by a moderator and notes were taken in required conditions. There were questions considering knowledge and views of participators about family planning, intrauterine device, IUD usage and acquisition, adverse effects, advantages, disadvantages, protectiveness and protectiveness duration of IUD in the interview guide. The interviews lasted about 30 minutes. In the first phase of data analysis, sound recordings were analysed by transferring to transcript word by word using Microsoft Word program, and later, these analyses were evaluated. Debate analysis and all sorts of concepts and expressions were examined in detail and placed under the questions in the interview guide. Thus, the main and sub-themes were constructed and analysed.

\section{RESULTS}

In this study, $26.7 \%$ of the participants graduated from primary school, $20.0 \%$ of them from secondary school, $33.3 \%$ of them from high school and $20.0 \%$ of the participants graduated from a university. Also, $66.7 \%$ of the participants had two and less than two children; $33.3 \%$ of them had three and more children. The interview data extracts were provided in italics below.

\section{General information about IUD}

While most of the men participating in this research specified IUD as a family planning method used by women, some mixed IUD with other methods. In addition, some of the participators had no information about IUD as the interview data extracts below showed:

- 'As far as I know, IUD is placed to the vagina of women. It is shaped like a tube.' (Participant aged 54, retired, bigh school)

- 'You mean binding? We know this within our community. Binding cervix. As I know, when you once bind your cervix, you will never get pregnant again.' (Participant aged 59, retired, university)

- 'I have heard this before. There are spirals used by men and used by women and it is a plastic preservative.' (Participant aged 58, retired, university)

- 'I don't know what a spiral is because I haven't thought of it before. We are dealing with internet all day; when we encounter these kinds of staff, we are not interested. I 
don't care what people use or do.' (Participant aged 29, artisan, bigh school)

Participants provided hesitant and wrong answers about who can use the IUD method.

- 'There are types used by men and women can also use under the supervision of a doctor.' (Participant aged 58, retired, university)

- 'It is used for family planning. I think men use it.' (Participant aged 52, worker, primary school)

- 'As I know it is used by men. Men put spiral to the thing, for blocking leakage.' (Participant aged 67, artisan, secondary school)

Participants gave different and quite wrong answers about who can use the IUD and where they can use:

- 'Of course, since it is a surgical procedure, it is implanted in the public hospital. If you go any other place to make it implanted and something goes wrong, the doctor will ask you why you did not go to the public hospital and let an unprofessional to do it.' (Participant aged 59, retired, university)

- 'Actually, I bave no idea. It is implanted in the community primary healthcare centers and some trained women place it themselves.' (Participant aged 54, retired, bigh school)

+ 'Where did we implement [... ] last time it was a bealthcare center. Women can express themselves easily to women doctors. Since there are women doctors in the healthcare centers, they choose to go there.' (Participant aged 53, worker, primary school)

- 'Generally, it is bought from pharmacies.' (Participant aged 52, worker, primary school)

\section{Effects, advantages and disadvantages of the IUD}

Some of the men participating in the research assessed the IUD as an advantageous method. In addition, some of them indicated not needing to use condom between its advantages:

- 'I think the most advantageous one is the IUD. People say pills cause weight. With other methods that men use, some of my friends' wives got pregnant.' (Participant aged 43, officer, secondary school)

- 'When women want to have children, they can take it out; and when they want to continue protection, they can make it implanted again. It is an advantage of using the IUD.' (Participant aged 26, worker, high school)

- 'Men who don't want to use condom, get their wives to use IUD and they don't use a condom. They do not need to.' (Participant aged 38, artisan, university)

Participants defined disadvantages of the IUD and its adverse effects on women and men during intercourse. While their knowledge about adverse effects of the IUD on women was mostly accurate, there were participators who gave hearsay information:

- 'Of course some may have intense bleeding. Some gain weight or lose weight. These kind of effects might occur.' (Participant aged 43, officer, secondary school)

- 'Certainly, harmful effects may occur, for example, there is a possibility to be exposed to inflammation.' (Participant aged 53, officer, secondary school)

+ 'One of my friends' wife was using spiral. Women drudge at home and carry heavy staff. After carrying a great number of furniture, the spiral moved from its place and she got pregnant. I heard this story from my friend, it is real.' (Participant aged 52, worker, primary school)

- 'It has advantages and disadvantages. I think, it has negative effects on people having orgasm and pleasing themselves.' (Participant aged 58, retired, university)

\section{Protectiveness of the IUD and its duration}

Participants did not have enough information about protectiveness of the IUD and its duration:

- 'The most protective one is IUD. Condoms may explode and they generally explode. Moreover, women may forget taking pills. They may think, they have taken. Probably, IUD may protect almost one year.' (Participant aged 26, pharmacy technician, high school)

- "People say 10 years, anybow I think it protects for 7 or 8 years.' (Participant aged 45, private security, high school)

\section{DISCUSSION}

Adopting a qualitative research method, this study aimed to investigate knowledge and approach of married men towards the IUD. While there many studies focusing on women about the IUD in the literature, there is only a small number of studies considering men. To our knowledge, there is not any research conducted with married men about the IUD, which is the most preferred modern method in Turkey makes this study significant.

Men who participated in this research did not have generally enough information about the IUD. They had more information about family planning but had low level of knowledge about details. Research conducted in 
Turkey also indicated that the knowledge level of men about the details of modern methods was low [9]. Moreover, other studies carried out in Turkey also demonstrated that knowledge of men about the IUD came after their knowledge about withdrawal and condom [10]. The reason laying behind unawareness of men about the IUD might be their low participation in family planning and their belief about the relevance of the issue since they think it is related to women. Men do not talk to each other about this issue, and this may influence the result as well. Social communication is indicated as the main source of their knowledge about methods. Notably, since they can talk to each other about the subject, they can improve their level of knowledge. In the literature, the importance of social networking is underlined and peer education is indicated as a significant strategy [11]. Increase of information of men about IUD will escalate their participation in family planning and decision-making process of the IUD method. This will also have an influence on women who cease using the IUD method. Research demonstrated that participation of men to the decision-making process of the IUD method decrease method abandonment rates [12].

Participants generally responded hesitantly or gave wrong answers to the questions concerning who could use IUD. A study conducted in the USA demonstrated that only about half of the men knew who could use IUD [13]. In addition, men did not have enough information about where IUD could be implemented. In Turkey, family planning methods and IUD are provided in every step by the state. Consultancy services relating to all methods of family planning are provided by health personnel trained in this regard. IUD can be implemented by trained, certified family physicians, midwives and nurses, especially in the primary healthcare centers and other healthcare centers by gynecologists. Primary health care centers take over significant responsibility in this issue. Studies conducted in Turkey also revealed that most of the users provided this method from healthcare centers owned by the state, especially from primary healthcare centers $[2,10]$.

Participants, who thought IUD was advantageous, explained IUD with its superiority over other methods. Participants had heard about women getting pregnant in spite of using other methods. In addition, they thought utilization of other modern methods could result in various adverse effects. This belief and thoughts about IUD, easy utilization of IUD and return of fertility after removal were demonstrated as advantages of IUD by the participators. In other qualitative research about IUD, participants also expressed positive feedback of people experienced IUD before, easy return of fertility and not seeing adverse effects encountered in other methods as advantageous aspects of this method $[14,15]$. Some of the participants indicated not having the need to use condom as an advantage of IUD. This underlines that men do not want to have responsibility about family planning and they intent to load this responsibility to women.

Participants defined disadvantages of IUD and its adverse effects on women and men during intercourse. They expressed excessive bleeding and pain as adverse effects of IUD on women. In the literature similar to the research results obtained in this study, excessive and irregular bleeding and pelvic pain were indicated as adverse effects of IUD $[4,8,12]$. It was observed that married men participating in this research had accurate information about this issue. Studies indicated that men were interested in and concerned about adverse effects of family planning methods $[16,17]$. In addition, these adverse effects were specified as reasons for quitting IUD method [2].

It was observed that participants had rumours and interesting information about the adverse effect and disadvantages of IUD on men during intercourse. Men stated that there could be pain during intercourse, orgasm problems or other disturbances due to outbreak of the IUD string. A qualitative study conducted in Turkey designated that there were rumours and wrong information about the disadvantages of IUD. Most expressed ones were as follows: weight gaining and losing, headache, nervous temperament, wounds, infection, stomach-ache, vein distention, unrest and pain during intercourse, infertility, cancer and dislocation of IUD inside the body [11]. Other studies conducted with men about IUD frequently indicated corrosion of IUD, unrest during intercourse, dislocation and sliding of IUD in woman's body as disadvantages of IUD $[4,13,18]$. Moreover, in the other studies, pain and unrest during intercourse were featured as disadvantages. It was observed that men did not want IUD utilization and insisted on removal due to these disadvantages existing during intercourse [12,14]. All these misinformation, rumours and myths are posing a serious obstacle to the use of modern family planning methods, including IUD. Even people do not believe all these misinformation, question marks in the minds of people could grow and these could decrease the trust of people towards modern family methods $[9,11]$. Men declared a negative opinion on the use of IUD by their wives or expressed their fears. This results in women abandoning to 
use the method, or they are made to quit by their spouses $[4,7,19]$. Health personnel will play a significant role in the elimination of misinformation and diminishing the effects of rumors and myths about IUD because IUD is applied in healthcare centers by trained medical personnel. Both women and men being informed about the subject, especially in primary healthcare centers will have a significant effect on demolishing misinformation, augment the trust of people on this method and lead people to choose this method consciously. In addition, men being informed about this subject will be effective in their participation and promote their responsibility in family planning. Hence, by providing family planning services to reach wider segments of society, the effectiveness of these services will be augmented.

There are some limitations to this study. First, this study was conducted only in one primary health care center in Umraniye. Also, a small sample was used. Therefore, this limits the generalization of study findings. Second, the sampled participants may have accepted to participate in this study due to their interest in subjects of health and family planning.

In conclusion, the men participating in this research have generally low level of knowledge on IUD. In addition, participators have misinformation on disadvantages and adverse effects of IUD. It was observed that misinformation of participators was generally shaped by rumors and myths. Especially, the training of men by health personnel about this issue will have a significant effect on the elimination of misinformation and rumors. Hence, participation of men in family planning decision making the process and to engage in informed choices will be provided as well. In addition, involving unmarried men and adolescents in family planning training will be important.

Ethics Committee Approval: In the application of this research, the principles of Helsinki Declaration were taken into consideration and necessary permissions were taken from the local managers for the research.

Conflict of Interest: No conflict of interest was declared by the authors.

Financial Disclosure: The authors declared that this study has received no financial support.

Authorship Contributions: Concept - MFO, SH, MK; Design MFO, SH, MK; Supervision - MFO, SH, MK; Materials - MFO, SH, MK; Data collection \&/or processing - $\mathrm{SH}$; Analysis and/or interpretation - SH, MFO; Writing - MFO, SH, MK; Critical review - MFO, SH, MK.

\section{REFERENCES}

1. Ahman EL, Shah IH. Contraceptive use, fertility, and unsafe abortion in developing countries. Eur J Contracept Reprod Health Care 2010;15:S77-82. [CrossRef]

2. Hacettepe University Institute of Population Studies. 2013 Turkey Demographic and Health Survey. Hacettepe University Institute of Population Studies, T.R. Ministry of Development and TÜBİTAK, Ankara, 2014.

3. Amy JJ, Tripathi V. Contraception for women: an evidence based overview. BMJ 2009;339:563-8. [CrossRef]

4. Khan A, Shaikh BT. An all time low utilization of intrauterine contraceptive device as a birth spacing method--a qualitative descriptive study in district Rawalpindi, Pakistan. Reprod Health 2013;10:10. [CrossRef]

5. Ali M, Rizwan H, Ushijima $\mathrm{H}$. Men and reproductive health in rural Pakistan: The case for increased male participation. Eur J Contracept Reprod Health Care 2004;9:260-6. [CrossRef]

6. de Irala J, Osorio A, Carlos S, Lopez-del Burgo C. Choice of birth control methods among European women and the role of partners and providers. Contraception 2011;84:558-64. [CrossRef]

7. Zeyneloglu S, Kisa S, Delibaş L. Determinants of family planning use among Turkish married men who live in South East Turkey. Am J Mens Health 2013;7:255-64. [CrossRef]

8. Denzin NK. Handbook of Qualitative Research. In: YS Lincoln, editor. Second edition. London: Sage Publications; 2000.

9. Cebeci Save D, Erbaydar T, Kalaca S, Harmanci H, Cali S, Karavus M. Resistance against contraception or medical contraceptive methods: a qualitative study on women and men in Istanbul. Eur J Contracept Reprod Health Care 2004;9:94-101. [CrossRef]

10. Altay B, Gonener D. Recognize and utilization of the family planning method among married males and the factors that affect the utilization of these services. [Article in Turkish]. Firat Tip Derg 2009;14:56-64.

11. Ay P, Hidiroglu S, Topuzoglu A, Ucar MS, Kose OO, Save D. Do perceived health risks outweigh the benefits of modern contraceptives? a qualitative study in a suburban population in Istanbul, Turkey. Eur J Contracept Reprod Health Care 2007;12:154-61. [CrossRef]

12. Bradley JE, Alam ME, Shabnam F, Beattie TS. Blood, men and tears: keeping IUDs in place in Bangladesh. Cult Health Sex 2009;11:543-58.

13. Borrero S, Farkas A, Dehlendorf C, Rocca CH. Racial and ethnic differences in men's knowledge and attitudes about contraception. Contraception 2013;88:532-8. [CrossRef]

14. Weston MR, Martins SL, Neustadt AB, Gilliam ML. Factors influencing uptake of intrauterine devices among postpartum adolescents: a qualitative study. Am J Obstet Gynecol 2012;206:40.e1-7. [CrossRef]

15. Bharadwaj P, Saxton JC, Mann SN, Jungmann EM, Stephenson JM. What influences young women to choose between the emergency contraceptive pill and an intrauterine device? A qualitative study. Eur J Contracept Reprod Health Care 2011;16:201-9. [CrossRef]

16. Karavus M, Cali S, Kalaca S, Cebeci D. Attitudes of married individuals towards oral contraceptives: a qualitative study in Istanbul, Turkey. J Fam Plann Reprod Health Care 2004;30:95-8. [CrossRef]

17. Ortayli N, Bulut A, Ozugurlu M, Çokar M. Why withdrawal? Why not withdrawal? Men's perspectives. Reprod Health Matters 2005;13:164-73.

18. Adongo PB, Tapsoba P, Phillips JF, Tabong PT, Stone A, Kuffour E, et al. The role of community-based health planning and services strategy in involving males in the provision of family planning services: a qualitative study in Southern Ghana. Reprod Health 2013;10:36. [CrossRef]

19. Alnakash AH. Influence of IUD perceptions on method discontinuation. Contraception 2008;78:290-3. [CrossRef] 